\title{
Plant growth-promoting rhizobacterium Pseudomonas PS01 induces salt tolerance in Arabidopsis thaliana
}

\author{
Thanh Nguyen Chu ${ }^{\dagger}$, Bao Thi Hoai $\operatorname{Tran}^{\dagger}$, Le Van Bui and Minh Thi Thanh Hoang ${ }^{*}$ (D)
}

\begin{abstract}
Objectives: Plant growth-promoting rhizobacteria (PGPR) may contribute to sustainable crop production by improving plant growth and/or plant tolerance to abiotic stresses. Soil salinity, which limits the productivity of crop plants, is one of the major concerns of modern agriculture, especially in countries heavily affected by climate change as Vietnam. Currently, only a few reports have studied local PGPR isolated in Vietnam, particular Pseudomonas. Therefore, our study aimed to isolate and identify a region-specific Pseudomonas strain and evaluate the effects of this strain on germination, growth promotion and gene expression of Arabidopsis thaliana under salt stress.

Results: The Pseudomonas named PS01 was isolated from maize rhizosphere collected in Ben Tre province, Vietnam. This strain was identified as a member of the Pseudomonas putida subclade. Pseudomonas PS01 could improve the germination rate of Arabidopsis seeds in $150 \mathrm{mM} \mathrm{NaCl}$. A. thaliana plants inoculated with Pseudomonas PSO1 survived under salt stress conditions up to $225 \mathrm{mM} \mathrm{NaCl}$, while all non-inoculated plants were dead above $200 \mathrm{mM} \mathrm{NaCl}$. The transcriptional levels of genes related to stress tolerance showed that only LOX2 was up-regulated, while APX2 and GLYI7 were down-regulated in inoculated plants in comparison to the non-inoculated controls. In turn, RD29A and RD29B did not show any significant changes in their expression profiles.
\end{abstract}

Keywords: Arabidopsis thaliana, Plant growth-promoting rhizobacteria (PGPR), Pseudomonas PS01, Salt stress tolerance

\section{Introduction}

Soil salinity is a widespread problem that limits crop yield and cultivation throughout the world, including the Mekong Delta, Vietnam [1]. Salinity creates ion imbalance and generates highly reactive oxygen species (ROS) in plants, which causes ion toxicity and oxidative stress $[2,3]$. This, in turn, leads to plant growth inhibition, slower development, senescence and death. To improve plant salinity tolerance, several strategies, such as the use of fertilizers, traditional breeding and genetic engineering, have been extensively studied for decades

\footnotetext{
*Correspondence: httminh@hcmus.edu.vn

†Thanh Nguyen Chu and Bao Thi Hoai Tran contributed equally in this article

Department of Plant Biotechnology and Biotransformation, Faculty of Biology and Biotechnology, University of Science, Vietnam National University-Ho Chi Minh City, Ho Chi Minh City, Vietnam
}

[4]. The application of plant growth-promoting rhizobacteria (PGPR) is one of the most promising alternative approaches to improve crop production in saline soils [2, 4, 5]. Various salt-tolerant PGPR including Azospirillum, Burkholderia, Rhizobium, Pseudomonas, Acetobacter and Bacillus have been successfully applied or tested for plant growth promotion under salt stress $[6,7]$. The fluorescent Pseudomonas is considered an important model to assess beneficial plant-bacteria interactions, including plant growth promotion under abiotic stress $[8,9]$. Inoculation of plants with Pseudomonas was found to alleviate salinity effects on plant development by reducing the uptake of toxic ions, inducing systemic resistance, producing phytohormones, increasing nutrient uptake and establishing root colonization [10-14]. Pseudomonas-induced salt tolerance has been mainly studied at the physiological and biochemical levels in plants. However, little is 
known about the transcriptional changes of plant saltresponsive genes in an interactive process [14].

To cope with salt stress, early plant responses include synthesis of ROS scavengers, detoxification of ROS and abscisic acid (ABA) signaling [15-17]. The glyoxalase pathway, which degrades methylglyoxal, is one of the main detoxification pathways [18]. In the ABA response, the expression of $R D 29$ (Responsive to Desiccation) genes including $R D 29 A$ and $R D 29 B$ is induced by salt stress [19]. PGPR may significantly enhance plant antioxidant activities, and thus protect plants from salt toxicity, by increasing the expression of enzymes such as ascorbate peroxidase (APX), superoxide dismutase (SOD) and catalase $[16,19,20]$. Interestingly, $A$. thaliana inoculated with PGPR such as Burkholderia phytofirmans PsJN and Enterobacter spp. EJ01 showed an enhanced tolerance to salt stress that involved transcriptional changes of genes related to early stress responses [16, 19].

It is necessary to identify native microbial strains which can be used in regional crops as potential plant growth promoters to achieve desirable yields [21]. The application of indigenous PGPR will provide more advantages for regional crops since PGPR can easily acclimatize to the local environmental conditions and enhance the plant-microbe interactions [22]. In previous study, we successfully isolated and identified some Pseudomonas spp. capable of enhancing plant growth in Vietnam [23]. Therefore, in this study, we aimed to isolate a Pseudomonas strain that can increase salt stress tolerance and to investigate the underlying molecular mechanisms.

\section{Main text}

\section{Materials and methods}

\section{Bacterial isolation}

Rhizobacteria were isolated from maize (Zea mays L.) rhizosphere collected in Ben Tre province, Vietnam. A soil suspension was obtained by shaking roots with adhered soil in phosphate-buffered saline for $10 \mathrm{~min}$ at $180 \mathrm{rpm}$. The suspension was serially diluted, spread onto King'B medium (KB) [24] and incubated at $30^{\circ} \mathrm{C}$ for $24 \mathrm{~h}$. A single colony was picked up and re-cultured a few times on solid KB to obtain a pure culture. The presence of fluorescent Pseudomonas was examined under UV light. Total isolates were grown on different concentration $\mathrm{NaCl}(0-10 \%)$ to evaluate salt tolerance property.

\section{Bacterial identification}

For phenotyping, the bacterial strain was identified according to morphological and chemotaxonomic characters based on the Bergey's Manual of Determinative Bacteriology. For genotyping, bacterial genomic DNA was extracted and purified using the Wizard Genomic DNA purification kit (Promega, USA). The complete
16S rDNA was amplified by using PCR with the universal bacterial primers $27 \mathrm{~F}$ and $1492 \mathrm{R}$ (Additional file 1: Table S1) [25]. The PCR product was sequenced and analyzed with BLASTn to identify the strain genus. Simultaneously, a fragment of rpoD gene was amplified by using the primers rpoD 70F and rpoD 70R (Additional file 1: Table S1) [26, 27]. The sequences of related species and genera were obtained from GenBank. Multiple sequence alignments were performed by ClustalX; the phylogenetic analysis was determined by employing the neighbor-joining method. The phylogenetic tree was constructed with MEGA version 6 Software [28].

\section{Plant growth conditions and treatments}

To define whether the bacteria had an effect on the germination of Arabidopsis in normal and saline condition, sterilized and synchronized seeds were inoculated with bacterial suspension $\left(10^{6} \mathrm{CFU} / \mathrm{ml}\right)$, or $\mathrm{MgCl}_{2}$ solution as a control or nongrowth-promoting strain Escherichia coli $\mathrm{DH} 5 \alpha$ as a negative control, and germinated on solid, half-strength Murashige and Skoog medium (MS $1 / 2$ ) plates with or without $150 \mathrm{mM} \mathrm{NaCl}$. Plates were placed in a growth chamber at $22{ }^{\circ} \mathrm{C}$ with a photoperiod of 16/8 h (light/dark). Four days after sowing (DAS), the seed germination percentage was determined.

To investigate the effect of Pseudomonas PS01 on Arabidopsis salt tolerance under different $\mathrm{NaCl}$ concentrations, 4-day-old seedlings were transferred to solid MS $1 \frac{1}{2}$ supplemented with different concentrations of this salt. Plates were placed vertically in a growth chamber at $22{ }^{\circ} \mathrm{C}$ with a photoperiod of $16 / 8 \mathrm{~h}$ (light/dark). After 7 days, the plant survival rate was determined.

\section{RNA extraction and real-time PCR (RT-PCR) analyses}

RNA extraction was performed on plantlets after being transplanted to MS $1 / 2$ alone or supplemented with $150 \mathrm{mM} \mathrm{NaCl}$ for $24 \mathrm{~h}$. RNA was obtained by using the Trizol (Invitrogen ${ }^{\mathrm{TM}}$, USA) method. RT-PCR was performed by using the Luna Universal One-Step RT-PCR Kit (New England Biolabs, USA). PCR primers are shown in Additional file 2: Table S2. The relative transcript level (RTL) was calculated by normalizing to $A C T 2$ as follows: $\mathrm{RTL}=2^{\Delta \Delta \mathrm{Ct}}$, where $\Delta \Delta \mathrm{Ct}=\Delta \mathrm{Ct}($ gene $)-\Delta \mathrm{Ct}(A C T 2)$. All experiments were performed with three biological and two technical replicates.

\section{Statistical analysis}

For comparison between treatments, ANOVA was performed with Graphpad Prism 7.0. 


\section{Results}

\section{Identification of bacteria}

Seventeen rhizobacterial strains were isolated from maize rhizosphere. The salt tolerant properties results revealed that out of 17 bacterial isolates tested; only isolate named PS01 was able to grow in the presence of $8 \% \mathrm{NaCl}$ (Additional file 3: Fig. S1). Based on its growth curve, PS01 strain has an optimal growth temperature of $30{ }^{\circ} \mathrm{C}$. Morphological and chemotaxonomic analyses revealed that PS01 is rod-shaped, Gram-negative, aerobic, non-sporeforming, catalase-positive and oxidase-positive, and fluoresces under UV light at $365 \mathrm{~nm}$ (Additional file 4: Fig. S2). The BLAST search of $16 \mathrm{~S}$ rDNA against the GenBank indicated that PS01 is most similar to Pseudomonas spp. In this genus, the rpoD gene has been identified as one of the best biomarkers for gene phylogeny, which correlates well with that of the $16 \mathrm{~S}$ rRNA gene [26, 27, $29,30]$. Therefore, rpoD was used to identify PS01 in our study. The phylogenetic tree of rpoD gene indicated that PS01 belongs to the Pseudomonas putida subclade (Fig. 1).

\section{Pseudomonas PSO1 enhances seed germination rate in salt stress conditions}

To test whether PS01 could enhance the germination rate of $A$. thaliana, its effect was examined in MS $1 / 2$ media with or without $150 \mathrm{mM} \mathrm{NaCl}$. We observed that the germination rate in the $150 \mathrm{mM} \mathrm{NaCl}$ treatment was significantly increased in PS01-inoculated seeds when compared to the control. PS01-treated A. thaliana seeds showed $30.7 \%$ germination rate, while this value was only
9.5\% in the control (Fig. 2a). However, no significant difference in the seed germination rate could be observed between the inoculated and non-inoculated seeds in MS $1 / 2$, suggesting that the PS01 treatment has no effect on $A$. thaliana germination in normal conditions.

\section{Pseudomonas PSO1 enhances salt stress tolerance}

To address the effects of $\mathrm{NaCl}$ and PS01 on A. thaliana salt tolerance in vitro, the survival rates (\%) of PS01inoculated and non-inoculated plants grown on media supplemented with $\mathrm{NaCl}$ concentrations ranging from $75 \mathrm{mM}$ to $225 \mathrm{mM}$ were evaluated. On the 7 th day after being transferred to the salt stress media, Arabidopsis seedlings were observed and photographed to identify the number of surviving plants.

PS01 root colonization was shown to increase the survival of plants exposed to saline concentrations ranging from 75 to $225 \mathrm{mM} \mathrm{NaCl}$ (Additional file 5: Fig. S3). For instance, all plants inoculated with PS01 could survive the $175 \mathrm{mM} \mathrm{NaCl}$ treatment as opposed to only $30-40 \%$ of the controls (Fig. 2b). These results suggest that Pseudomonas PS01 may enhance $A$. thaliana survival under salt stress.

\section{Pseudomonas PSO1 induces transcriptional changes in salt-stressed $A$. thaliana plants}

To investigate the molecular mechanisms of PS01induced salt stress tolerance in Arabidopsis, some genes related to early salt stress responses such as ROS scavenging ( $A P X 2)$, detoxification (GLYI7), ABA signaling (RD29A and $R D 29 B)$ and JA synthesis (LOX2) were

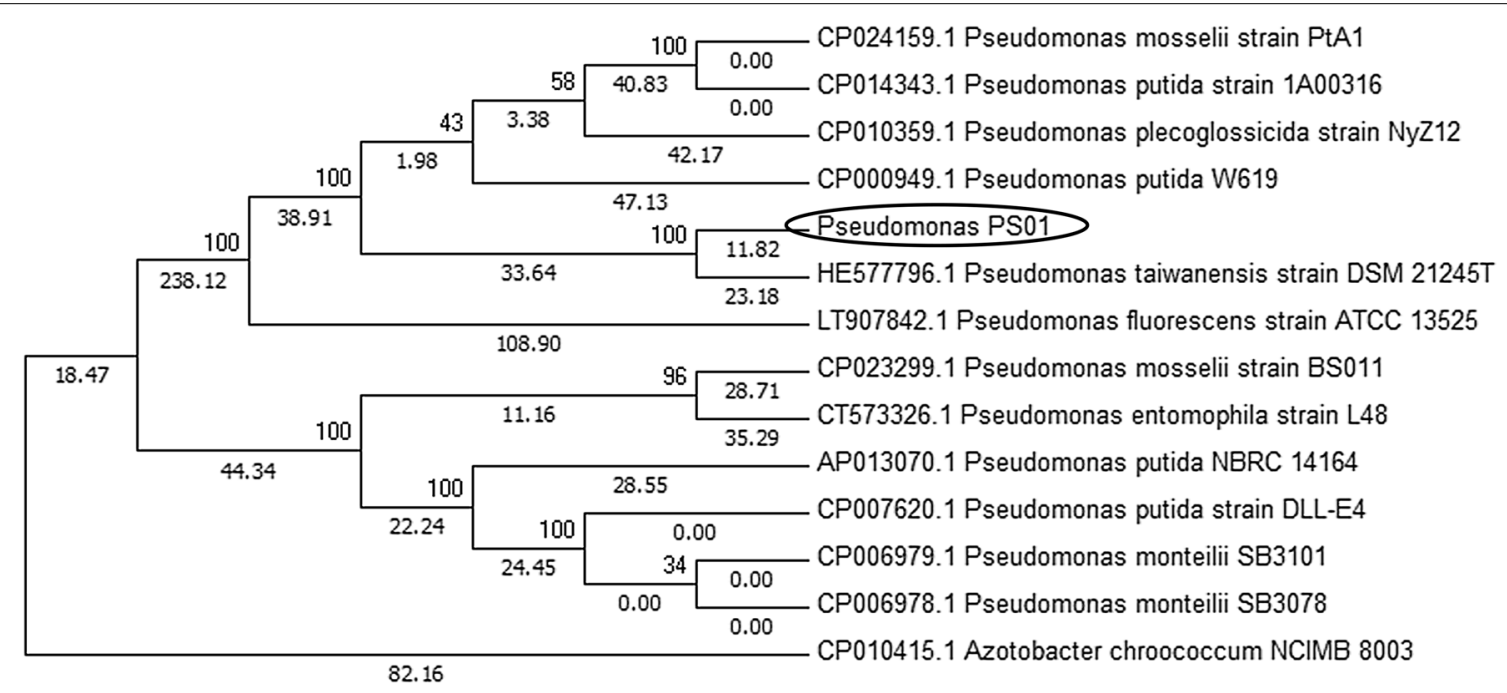

Fig. 1 Phylogenetic tree based on rpoD gene sequences of Pseudomonas PS01, related Pseudomonas strains and Azotobacter chroococcum. The sequence of Pseudomonas PS01 showed 99\% similarity to Pseudomonas taiwanesis strain (GenBank accession number HE577796.1). The bootstrap values are inferred from 1000 replicates. Branch lengths are presented to phylogenetic distances 

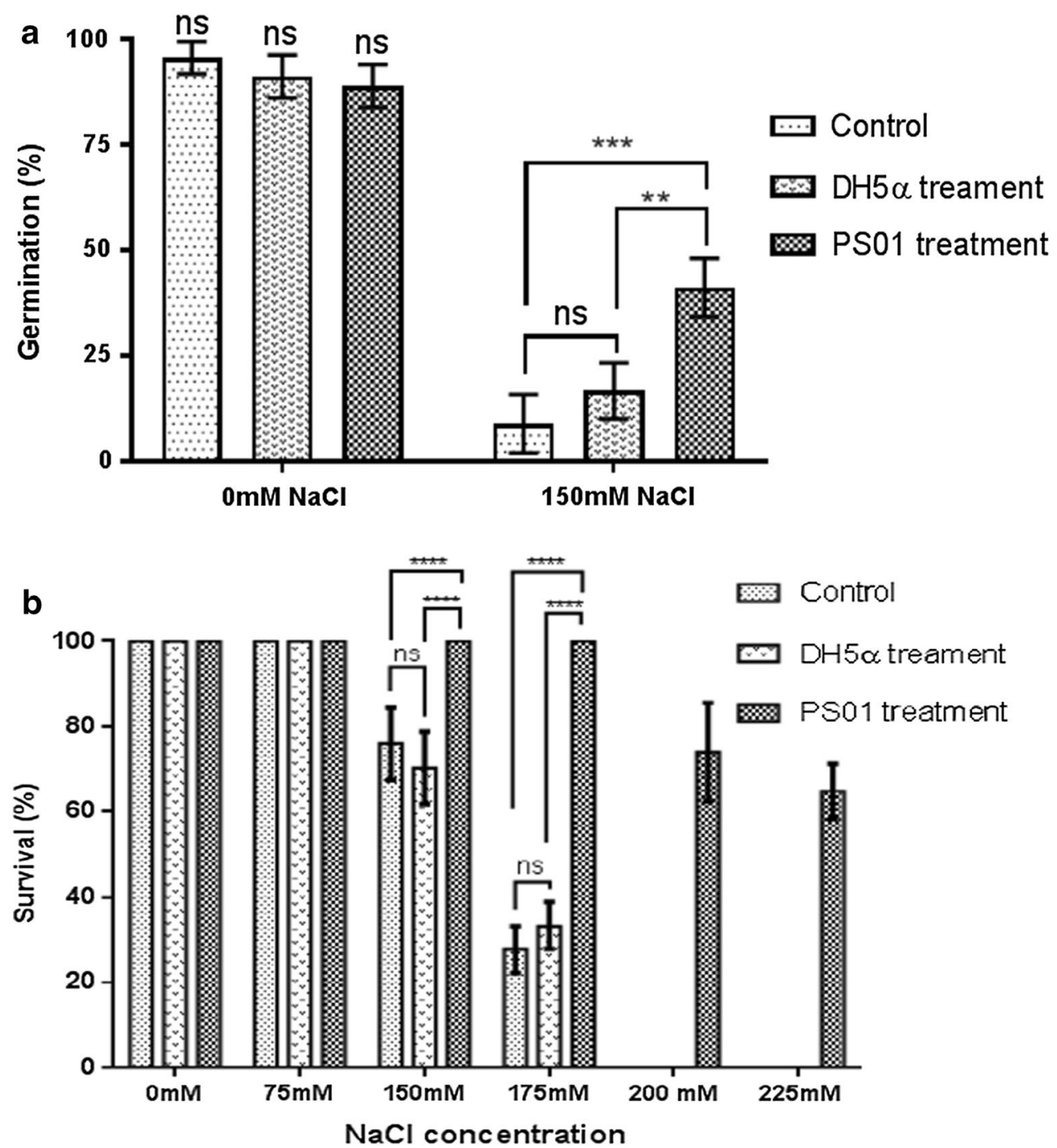

Fig. 2 Pseudomonas PS01 enhances Arabidopsis thaliana germination and survival under high saline concentration. Germination rate of non-inoculated, inoculated DH5a and inoculated PS01 Arabidopsis seeds in MS 1 1/2 medium alone and with $150 \mathrm{mM} \mathrm{NaCl}$ added (a). Survival rate (\%) of non-inoculated, DH5a-inoculated and PS01-inoculated plants grown on medium supplemented with different $\mathrm{NaCl}$ concentrations (b). Data are represented as mean \pm SE of at least 30 seeds or plants per treatment. Experiments were repeated at least three times with similar results. ${ }^{* *}, * * *$,

****Indicates the significant difference between both treatments (control vs PS01-inoculated) at $p$ value $<0.01,<0.001$ and $p<0.0001$, respectively

chosen for quantitative RT-PCR analysis. The gene expression profiles of these genes were obtained from 4 different samples: seedlings inoculated or non-inoculated with PS01 and grown in MS $1 / 2$ alone or transferred to MS $1 / 2$ supplemented with $150 \mathrm{mM} \mathrm{NaCl}$.

After $24 \mathrm{~h}$ salt stress, the transcriptional expression of all five genes was remarkably up-regulated compared to the control (seedlings grown on MS $1 / 2$ alone). The analyses showed no differences in $R D 29 A$ and $R D 29 B$ expression in PS01-inoculated and non-inoculated seedlings under the $\mathrm{NaCl}$ treatment. By contrast, LOX2 expression was up-regulated in PS01-inoculated, salt-stressed plants, while APX2 and GLYI7 were significantly downregulated (Fig. 3).

\section{Discussion}

PS01 is the first Pseudomonas strain isolated in Vietnam which alleviates the effect of salinity on plant growth. PS01 belongs to the Pseudomonas putida subclade based on the rpoD gene tree (Fig. 1), being closely related to $P$. taiwanensis (GenBank accession number HE577796.1). Interestingly, $P$. putida was already known to reduce the detrimental effect of salinity on germination and plant growth $[7,31]$. 

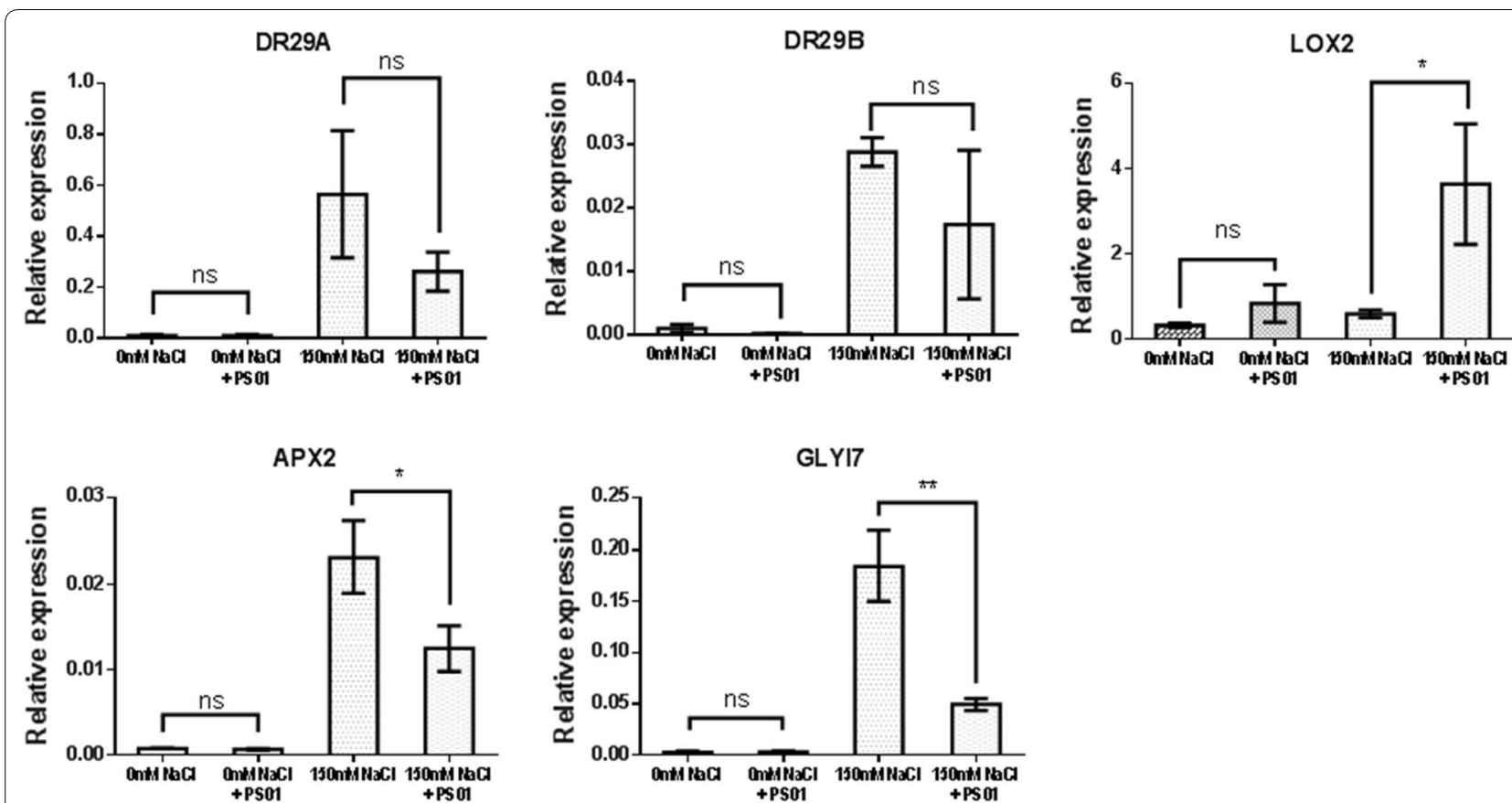

Fig. 3 Gene expression analysis of abiotic stress-responsive genes of Arabidopsis seedlings inoculated with Pseudomonas PSO 1 after $24 \mathrm{~h}$ of being transferred to salt stress conditions. The transcriptional levels of RD29A, RD29B, LOX2, APX2 and GLYI7 of PS01-inoculated and non-inoculated A. thaliana seedlings grown in MS $1 / 2$ alone or transferred to MS $1 / 2$ supplemented with $150 \mathrm{mM} \mathrm{NaCl}$ are represented. Experiment was performed with three biological and two technical replicates $\left(^{*}\right)$ and $\left(^{* *}\right)$ indicate the significant difference between both treatments $(150 \mathrm{mM} \mathrm{NaCl}$ vs $150 \mathrm{mM}$ $\mathrm{NaCl}+$ PS01 inoculated) at $p$ value $<0.05$ and $p<0.01$, respectively

In this study, Pseudomonas PS01 improved the germination rate of $A$. thaliana on salt stress medium (MS $1 / 2$ supplemented with $150 \mathrm{mM} \mathrm{NaCl}$ ). Compared to previous studies focusing on the effect of bacteria on plant growth, the germination process was accelerated and its period was also extended [32]. For example, $P$. putida R4 and $P$. chlororaphis $\mathrm{R} 5$ improved cotton seed germination in response to $\mathrm{NaCl}$ stress up to 64 and 73\%, respectively [7]. In contrast, Pseudomonas spp. PDMZnCd2003 negatively affected rice germination, and reduced seedling shoot and root length [33]. We have shown that PS01 helps improve salt stress tolerance in A. thaliana seedlings. Under salt stress conditions, the transcriptional level increase of GLYI7 and APX2 in seedlings inoculated with PS01 was lower than that of non-inoculated seedlings. Glyoxalase can be considered as an alarm in the abiotic stress response in plants [34]. In turn, ascorbate peroxidases catalyze the conversion of $\mathrm{H}_{2} \mathrm{O}_{2}$ into $\mathrm{H}_{2} \mathrm{O}$. The down-regulation of GLYI7 and APX2 suggests that inoculation with PS01 may reduce stress level in plants. Therefore, the mechanisms contributing to the survival of inoculated plants during salt stress can be related to other molecular pathways. Alternatively, the production of biofilms by the bacteria could be beneficial to plant survival under stress conditions as shown in recent reports, in which bacterial exopolysaccharide (EPS) and biofilm formation stimulated plant growth under salt stress by reducing $\mathrm{Na}^{+}$uptake by the plant $[20,35]$. However, further evidences for EPS production or other putative mechanisms participating in the PS01-mediated salt tolerance of plants need to be verified.

Jasmonate (JA) is a positive regulator of the salt stress response that accumulates rapidly when plants are submitted to stress [20,36]. LOX2 encodes a lipoxygenase that constitutes an essential component of the JA synthesis pathway [37]. Compared to non-inoculated seedlings in response to salt stress, the increase of $L O X 2$ expression in PS01 inoculated seedlings in our study is in agreement with Cho et al. [14] and Poupin et al. [38], who also reported that PGPR such as Pseudomonas chlororaphis $\mathrm{O6}$ and Burkholderia phytofirmans PsJN mediated systemic resistance against abiotic stress by increasing the expression of defense genes regulated by the JA pathway [14, 38]. The phenotypic changes, transcriptional profile and spatiotemporal responses under salt stress of plants inoculated with PS01 will be analyzed at different plant growth stages to clarify this pathway. 


\section{Conclusion}

Our study has shown that Pseudomonas PS01 can improve Arabidopsis thaliana germination and survival rate under salt stress.

\section{Limitations}

Although, mechanism underlying PS01-Arabidopsis interaction to enhance plant salt tolerance has not been fully discovered, further studies have been conducting in our group to provide new insights into this interaction including whole genome analysis and transposon mutant library screening of PS01, as well as long-term transcriptomic analysis of plants inoculated with this isolate. PS01 will be inoculated with maize under salt stress and be developed as a biofertilizers in the future prospect.

\section{Additional files}

Additional file 1: Table S1. Primers used to amplify 16S DNA and rpoD gene.

Additional file 2: Table S2. List of RT-PCR primers used in this study.

Additional file 3: Figure S1. Growth of Pseudomonas PS01 on TSB medium at different $\mathrm{NaCl}$ concentrations: $0 \%(A), 2 \%$ (B), 4\% (C), 6\% (D), $8 \%(\mathrm{E})$ and $10 \%(\mathrm{~F})$

Additional file 4: Figure S2. Pseudomonas PS01 colonies on King's B medium (A) and visualization of fluorescent colonies under UV light (B). Picture B was taken using $365 \mathrm{~nm}$ as excitation wavelength. Gram staining of Pseudomonas PS01 cells (C).

Additional file 5: Figure S3. Effects of $\mathrm{NaCl}$ and PSO1 on A. thaliana salt tolerance in vitro under different $\mathrm{NaCl}$ concentrations. Non-inoculated A. thaliana grown on $\mathrm{MS} 1 / 2$ supplemented with $\mathrm{NaCl} 0 \mathrm{mM}(\mathrm{A} 1), \mathrm{NaCl}$ $75 \mathrm{mM}$ (A2), NaCl $150 \mathrm{mM}$ (A3), $175 \mathrm{mM}$ (A4), $200 \mathrm{mM}$ (A5), $225 \mathrm{mM}$ (A6). A. thaliana inoculated with $E$. coli grown on $\mathrm{MS} 1 / 2$ supplemented with $\mathrm{NaCl}$ $0 \mathrm{mM}$ (B1), NaCl $75 \mathrm{mM}$ (B2), NaCl $150 \mathrm{mM}$ (B3), $175 \mathrm{mM}$ (B4), $200 \mathrm{mM}$ (B5), $225 \mathrm{mM}$ (B6). A. thaliana inoculated with PS01 grown on MS 1/2 supplemented with $\mathrm{NaCl} 0 \mathrm{mM}$ (C1), NaCl $75 \mathrm{mM}$ (C2), NaCl $150 \mathrm{mM}$ (C3), $175 \mathrm{mM}$ (C4), $200 \mathrm{mM}$ (C5), $225 \mathrm{mM}$ (C6). White bars in the photographs correspond to $1 \mathrm{~cm}$.

\section{Abbreviations}

ABA: abscisicacid; APX: ascorbateperoxidase; A. thaliana: Arabidopsis thaliana: DAS: days after sowing; EPS: exopolysaccharide; GLYI7: Glyoxalase I 7; JA: Jasmonate; KB: King'B medium; LOX2: Lipoxygenase 2; MS 1/2: half-strength Murashige and Skoog medium; PGPR: plantgrowth-promoting rhizobacteria; PS01: Pseudomonas PS01; RT-PCR: real-time PCR; RD29A: Relative to Dessication $A ; R D 29 B$ : Relative to Dessication $B ; R O S$ : reactive oxygen species; RTL: relative transcript level; SOD: superoxide dismutase.

\section{Authors' contributions}

TNC, BTHT and MTTH designed this research, performed the experiments, analyzed the data and wrote the manuscript. LVB reviewed of the literature and provided technical assistance to TNC. All authors read and approved the final manuscript.

\section{Acknowledgements}

We would like to thank Dr. Stéphane Mari (BPMP Montpellier, France) for providing Arabidopsis thaliana Col-0 seeds. We also thank Dr. Tran Hong Nha Nguyen (University of Science, VNU-HCMC, Vietnam), Dr. Tuan Minh Tran
(Nanyang Technological University, Singapore) and Dr. Ngoc Bui (Department of Molecular Oncology, H. Lee Moffitt Cancer Center, Tampa, Florida) for critical reading, editing and valuable suggestions for this manuscript.

\section{Competing interests}

The authors declare that they have no competing interests.

\section{Availability of data and materials}

The data supporting the conclusions of this article is included within the article and its additional files.

\section{Consent for publication}

Not applicable.

\section{Ethics approval and consent to participate}

Not applicable.

\section{Funding}

This research was funded by Vietnam National University-Ho Chi Minh City under Grant Number (C2018-18-19). The World Academy of Sciences (TWAS) supported the equipment and publication fee under research Grant Award numbers 16-142 RG/BIO/AS_I-FR3240293339. The funding bodies had no role in the design, collection, data analysis, interpretation and reporting of data or in writing the manuscript.

\section{Publisher's Note}

Springer Nature remains neutral with regard to jurisdictional claims in published maps and institutional affiliations.

Received: 16 August 2018 Accepted: 4 January 2019

Published online: 11 January 2019

\section{References}

1. Shrivastava P, Kumar R. Soil salinity: a serious environmental issue and plant growth promoting bacteria as one of the tools for its alleviation. Saudi J Biol Sci. 2015;22(2):123-31. https://doi.org/10.1016/j. sjbs.2014.12.001.

2. Numan M, Bashir S, Khan Y, Mumtaz R, Shinwari ZK, Khan AL, et al. Plant growth promoting bacteria as an alternative strategy for salt tolerance in plants: a review. Microbiol Res. 2018. https://doi.org/10.1016/j.micre s.2018.02.003.

3. Miller G, Suzuki N, Ciftci-Yilmaz S, Mittler R. Reactive oxygen species homeostasis and signalling during drought and salinity stresses. Plant Cell Environ. 2010;33(4):453-67. https://doi.org/10.111 1/j.1365-3040.2009.02041.x.

4. Choudhary DK, Varma A, Tuteja N. Plant-microbe interaction: an approach to sustainable agriculture. Life Sci. 2016. https://doi. org/10.1007/978-981-10-2854-0.

5. Yang J, Kloepper JW, Ryu CM. Rhizosphere bacteria help plants tolerate abiotic stress. Trends Plant Sci. 2009;14(1):1-4. https://doi. org/10.1016/j.tplants.2008.10.004.

6. Chatterjee P, Samaddar S, Anandham R, Kang Y, Kim K, Selvakumar G, et al. Beneficial soil bacterium Pseudomonas frederiksbergensis OS261 augments salt tolerance and promotes red pepper plant growth. Front Plant Sci. 2017;8(May):1-9. https://doi.org/10.3389/fpls.2017.00705.

7. Egamberdieva D, Jabborova D, Hashem A. Pseudomonas induces salinity tolerance in cotton (Gossypium hirsutum) and resistance to Fusarium root rot through the modulation of indole-3-acetic acid. Saudi J Biol Sci. 2015;22(6):773-9. https://doi.org/10.1016/j.sjbs.2015.04.019.

8. Sitaraman R. Pseudomonas spp. as models for plant-microbe interactions. Front Plant Sci. 2015;6:1-4. https://doi.org/10.3389/ fpls.2015.00787.

9. Saravanakumar D, Samiyappan R. ACC deaminase from Pseudomonas fluorescens mediated saline resistance in groundnut (Arachis hypogea) plants. J Appl Microbiol. 2007;102(5):1283-92. https://doi.org/10.111 1/j.1365-2672.2006.03179.x. 
10. Sarma RK, Saikia R. Alleviation of drought stress in mung bean by strain Pseudomonas aeruginosa. GGRJ21. 2013. https://doi.org/10.1007/s1110 4-013-1981-9.

11. Gururani MA, Upadhyaya CP, Baskar V, Venkatesh J, Nookaraju A, Park SW. Plant growth-promoting rhizobacteria enhance abiotic stress tolerance in Solanum tuberosum through inducing changes in the expression of ROS-scavenging enzymes and improved photosynthetic performance. J Plant Growth Regul. 2013;32(2):245-58. https://doi.org/10.1007/s0034 4-012-9292-6.

12. Bano A, Fatima M. Salt tolerance in Zea mays (L.) following inoculation with Rhizobium and Pseudomonas. Biol Fertil Soils. 2009;45(4):405-13. https://doi.org/10.1007/s00374-008-0344-9.

13. Egamberdieva D. Pseudomonas chlororaphis: a salt-tolerant bacterial inoculant for plant growth stimulation under saline soil conditions. Acta Physiol Plant. 2012;34(2):751-6. https://doi.org/10.1007/s1173 8-011-0875-9.

14. Cho SM, Park JY, Han SH, Anderson AJ, Yang KY, Gardener BMS, et al. Identification and transcriptional analysis of priming genes in Arabidopsis thaliana induced by root colonization with Pseudomonas chlororaphis O6. Plant Pathol J. 2011;27(3):272-9. https://doi.org/10.5423/ PPJ.2011.27.3.272

15. Habib SH, Kausar H, Saud HM. Plant growth-promoting rhizobacteria enhance salinity stress tolerance in Okra through ROS-scavenging enzymes. Biomed Res Int. 2016. https://doi.org/10.1155/2016/6284547.

16. Pinedo I, Ledger T, Greve M, Poupin MJ. Burkholderia phytofirmans PsJN induces long-term metabolic and transcriptional changes involved in Arabidopsis thaliana salt tolerance. Front Plant Sci. 2015;6(June):1-17. https://doi.org/10.3389/fpls.2015.00466.

17. Gupta B, Huang B, Gupta B, Huang B. Mechanism of salinity tolerance in plants: physiological, biochemical, and molecular characterization. Int J Genomics. 2014;2014:1-18. https://doi.org/10.1155/2014/701596.

18. Kwon K, Choi D, Hyun JK, Jung HS, Baek K, Park C. Novel glyoxalases from Arabidopsis thaliana. FEBS J. 2013;280(14):3328-39. https://doi. org/10.1111/febs.12321.

19. Kim K, Jang Y-J, Lee S-M, Oh B-T, Chae J-C, Lee K-J. Alleviation of salt stress by Enterobacter sp. EJ01 in tomato and arabidopsis is accompanied by up-regulation of conserved salinity responsive factors in plants. Mol Cells. 2014;37(2):109-17. https://doi.org/10.14348/molcells.2014.2239.

20. Liu S, Hao H, Lu X, Zhao X, Wang Y, Zhang Y, et al. Transcriptome profiling of genes involved in induced systemic salt tolerance conferred by Bacillus amyloliquefaciens FZB42 in Arabidopsis thaliana. Sci Rep. 2017;7(1):1-13. https://doi.org/10.1038/s41598-017-11308-8.

21. Fischer SE, Fischer SI, Magris S, Mori GB. Isolation and characterization of bacteria from the rhizosphere of wheat. World J Microbiol Biotechnol. 2007;23(7):895-903.

22. Verma JP, Yadav J, Tiwari KN, Kumar A. Effect of indigenous Mesorhizobium spp. and plant growth promoting rhizobacteria on yields and nutrients uptake of chickpea (Cicer arietinum L.) under sustainable agriculture. Ecol Eng. 2013;51:282-6. https://doi.org/10.1016/j.ecoleng.2012.12.022.

23. Chu NT, Nguyen YN, Dao ND, Tran THB, Hoang TTM, Bui VL. Evaluation of two Pseudomonas strains isolated from maize rhizosphere as plant growth promoting rhizobacteria. J Sci Techonol Dev. 2018;21(2):34-41.

24. King EO, Ward MK, Raney DE. Two simple media for the demonstration of pyocyanin and fluorescin. J Lab Clin Med. 1954;443017(1954):443017.
25. Lane DJ. 16S/23S rRNA sequencing. In: Stackebrandt E, Goodfellow M, editors. Nucleic acid techniques in bacterial systematics. New York, NY: John Wiley and Sons; 1991. p. 115-75. 1991;115-75.

26. Yamamotot $S$, Harayama S. Phyiogenetic relationships of Pseudomonas putida strains deduced from the nucleotide sequences of gyrB, rpoD and 16 s rRNA genes. Int J Syst Bacteriol. 1998;488(1):3-8.

27. Mulet M, Bennasar A, Lalucat J, García-Valdés E. An rpoD-based PCR procedure for the identification of Pseudomonas species and for their detection in environmental samples. Mol Cell Probes. 2009;23(3-4):140-7. https://doi.org/10.1016/j.mcp.2009.02.001.

28. Tamura K, Stecher G, Peterson D, Filipski A, Kumar S. MEGA6: molecular evolutionary genetics analysis version 6.0. Mol Biol Evol. 2013;30(12):2725-9. https://doi.org/10.1093/molbev/mst197.

29. Ghyselinck J, Coorevits A, Van Landschoot A, Samyn E, Heylen K, De Vos $P$. An rpoD gene sequence based evaluation of cultured Pseudomonas diversity on different growth media. Microbiology. 2013;159(Pt 10):2097108. https://doi.org/10.1099/mic.0.068031-0.

30. Rajwar A, Sahgal M. Phylogenetic relationships of fluorescent pseudomonads deduced from the sequence analysis of $165 \mathrm{SRNA}$, Pseudomonas-specific and rpoD genes. 3 Biotech. 2016;6(1):1-10. https://doi. org/10.1007/s13205-016-0386-x.

31. Jalili F, Khavazi K, Pazira E, Nejati A, Rahmani HA, Sadaghiani HR, et al. Isolation and characterization of ACC deaminase-producing fluorescent pseudomonads, to alleviate salinity stress on canola (Brassica napus L.) growth. J Plant Physiol. 2009;166(6):667-74. https://doi.org/10.1016/j. jplph.2008.08.004.

32. Mahmood S, Daur I, Al-Solaimani SG, Ahmad S, Madkour MH, Yasir M, et al. Plant growth promoting rhizobacteria and silicon synergistically enhance salinity tolerance of mung bean. Front Plant Sci. 2016. https:// doi.org/10.3389/fpls.2016.00876.

33. Nakbanpote W, Panitlurtumpai N, Sangdee A, Sakulpone N, Sirisom P, Pimthong A. Salt-tolerant and plant growth-promoting bacteria isolated from $\mathrm{Zn} / \mathrm{Cd}$ contaminated soil : identification and effect on rice under saline conditions. J Plant Interactions. 2014;91:45. https://doi. org/10.1080/17429145.2013.842000.

34. Kaur C, Singla-Pareek SL, Sopory SK. Glyoxalase and methylglyoxal as biomarkers for plant stress tolerance. CRC Crit Rev Plant Sci. 2014;33(6):42956. https://doi.org/10.1080/07352689.2014.904147

35. Upadhyay SK, Singh JS, Singh DP. Exopolysaccharide-producing plant growth-promoting rhizobacteria under salinity condition. Pedosphere. 2011;21(2):214-22. https://doi.org/10.1016/S1002-0160(11),60120-3.

36. Zhao Y, Dong W, Zhang N, Ai X, Wang M, Huang Z, et al. A wheat allene oxide cyclase gene enhances salinity tolerance via jasmonate signaling. Plant Physiol. 2014;164(2):1068-76. https://doi.org/10.1104/pp.113.22759 5.

37. Wasternack C, Hause B. Jasmonates: Biosynthesis, perception, signal transduction and action in plant stress response, growth and development: an update to the 2007 review in annals of botany. Ann Bot. 2013;111(6):1021-58

38. Poupin MJ, Timmermann T, Vega A, Zuñiga A, González B. Effects of the plant growth-promoting bacterium Burkholderia phytofirmans PSJN throughout the life cycle of Arabidopsis thaliana. PLOS ONE. 2013;8(7):22-4

Ready to submit your research? Choose BMC and benefit from:

- fast, convenient online submission

- thorough peer review by experienced researchers in your field

- rapid publication on acceptance

- support for research data, including large and complex data types

- gold Open Access which fosters wider collaboration and increased citations

- maximum visibility for your research: over $100 \mathrm{M}$ website views per year

At BMC, research is always in progress.

Learn more biomedcentral.com/submissions 